Article

\title{
Using Systematic Observations to Understand Conditions that Promote Interracial Experiences in Neighbourhood Parks
}

\author{
Amy Hillier ${ }^{1, *}$, Bing Han ${ }^{2}$, Theodore S. Eisenman ${ }^{3}$, Kelly R. Evenson ${ }^{4}$, Thomas L. McKenzie ${ }^{5}$ and Deborah A. \\ Cohen ${ }^{2}$ \\ ${ }^{1}$ City and Regional Planning, School of Design, University of Pennsylvania, Philadelphia PA, 19104, USA; \\ E-Mail: ahillier@upenn.edu \\ 2 RAND Corporation, Santa Monica CA, 90401, USA; E-Mails: bhan@rand.org (B.H.), dcohen@rand.org (D.C.) \\ ${ }^{3}$ Department of Landscape Architecture and Regional Planning, University of Massachusetts, Amherst MA, 01003, USA; \\ E-Mail: teisenman@umass.edu \\ ${ }^{4}$ Department of Epidemiology, Gillings School of Global Public Health, University of North Carolina-Chapel Hill, Chapel \\ Hill NC, 27599, USA; E-Mail: kelly_evenson@unc.edu \\ 5 Institute for Behavioral and Community Health, School of Exercise and Nutritional Sciences, San Diego State University, \\ San Diego CA 92115, USA; E-Mail: tmckenzi@mail.sdsu.edu
}

* Corresponding author

Submitted: 7 September 2016 | Accepted: 18 November 2016 | Published: 9 December 2016

\begin{abstract}
We analysed observations from 31 neighbourhood parks, with each park mapped into smaller target areas for study, across five US cities generated using the System for Observing Play and Recreation in the Community (SOPARC). In areas where at least two people were observed, less than one-third (31.6\%) were populated with at least one white and one non-white person. Park areas that were supervised, had one or more people engaged in vigorous activity, had at least one male and one female present, and had one or more teens present were significantly more likely to involve interracial groups ( $p<0.01$ for each association). Observations in parks located in interracial neighbourhoods were also more likely to involve interracial groups $(p<0.05)$. Neighbourhood poverty rate had a significant and negative relationship with the presence of interracial groups, particularly in neighbourhoods that are predominantly non-white. Additional research is needed to confirm the impact of these interactions. Urban planning and public health practitioners should consider the health benefits of interracial contact in the design and programming of neighbourhood parks.
\end{abstract}

\section{Keywords}

Intergroup Contact Theory; interracial contact; parks and recreation; SOPARC; urban parks

\section{Issue}

This article is part of the issue "Paradigm Shifts in Urban Planning", edited by Matthias Drilling (University of Applied Sciences and Arts Northwestern Switzerland, Switzerland), Efrat Eizenberg (Israel Institute of Technology, Israel), Janet Stanley (University of Melbourne, Australia), Lee Boon Thong (Nilai University, Malaysia) and Andreas Wesener (Lincoln University Canterbury, New Zealand).

(C) 2016 by the authors; licensee Cogitatio (Lisbon, Portugal). This article is licensed under a Creative Commons Attribution 4.0 International License (CC BY).

\section{Introduction}

Urban parks have held a prominent place in city planning, landscape architecture, and public health scholarship for well over a century (Cranz, 1982; Wheater et al., 2007). Recent literature has identified four potential pathways whereby green space in cities may promote public health: stress reduction, increased physical activity, improved air quality, and social cohesion (Hartig, Mitchell, de Vries, \& Frumkin, 2014). The first three of these pathways have received more scholarly attention than the democratic and social implications of people across race/ethnicity and 
socioeconomic status coming together in public spaces (Eisenman, 2016). Building from the concept of psychosocial health, this paper considers the role of parks in bringing people together across racial/ethnic groups and, potentially facilitating interracial contact as an important and underappreciated pathway to increasing social cohesion, reducing racial prejudice, and improving human health. We analyse observations from 31 neighbourhood parks in five US cities to determine the characteristics of parks, neighbourhoods in which the park is located, and activities offered at the park that correlate with people across racial groups simultaneously occupying the same part of the park. We conclude by calling on urban design and planning to focus on creating and managing public spaces that promote social interaction across race/ethnicity as well as income, gender, and age groups.

Before describing data collection and analysis methods, we review literature from four distinct areas of scholarship that together create the conceptual and methodological foundation for our research: (1) urban planning and landscape architecture's history of promoting urban parks as democratic public spaces that foster cohesion between groups of different socio-economic and ethnic background; (2) research on social interaction, social cohesion, and intergroup contact in public spaces and green spaces within leisure studies and environmental and social psychology; (3) public health research on chronic exposure to prejudice and institutional racism as primary contributors to racial health disparities; and (4) recent public health research utilizing systematic social observations and environmental audits of outdoor public spaces including neighbourhood parks. By borrowing from these distinct areas of scholarship, we present a conceptual framework and suggestions for measurement and research design that highlight and test the underappreciated public health benefits of people coming together across race and ethnicity in neighbourhood parks.

\section{Background and Significance}

\subsection{Urban Parks}

As the world undergoes a third major period of urbanization (Angel, 2011), local governments are adopting new types of parks and green space strategies. This includes creation of rail trails and greenways, retrofitting landfills, cemeteries, rooftops, and parking areas, covering highways and reservoirs, sharing schoolyards, closing roads, and creating urban farms and community gardens (Harnik, 2010). There is also increasing attention on tree planting and site scale greening initiatives (Keeley, 2011; Young, 2011). Situated within an historical context, this bloom of activity can be seen as an effort to increase the liveability of cities in an urbanizing age (Eisenman, 2016), in much the same way that reform-minded urban designers and leaders advanced city parks in the $19^{\text {th }}$ century (Schuyler, 1986).
Historically, social workers, urban planners, landscape architects and public health practitioners looked to parks as antidotes to many of the problematic and unhealthy aspects of cities (Dannenberg, Frumkin, \& Jackson, 2011). The $19^{\text {th }}$ century parks movement developed in response to the negative impact of urban industrialization on physical health, mental health, and social bonds (Cranz, 1982; Eisenman, 2013; Schuyler, 1986). Frederick Law Olmsted, Sr. the $19^{\text {th }}$ century landscape architect famous for designing Manhattan's Central Park, Brooklyn's Prospect Park, and Boston's Emerald Necklace, thought natural scenery was critical "to give the mind a suggestion of rest from the devouring eagerness and intellectual strife of town life" (Olmsted, 1870). Olmsted believed that parks would promote democratic values and social life by bringing together diverse people, "each individual adding by his mere presence to the pleasure of all others" (Olmsted, 1870).

The large, curvilinear "pleasure grounds" of the $19^{\text {th }}$ century that benefited primarily upper middle class residents gave way to the smaller, rectilinear "reform parks" of the early $20^{\text {th }}$ century, focused on social reform, children's play, and assimilation of European immigrants (Cranz, 1982; Cranz \& Boland, 2004). During the Progressive Era, parks were expected to "reduce class conflict, reinforce the family unit, to socialize immigrants to the American way of life, to stop the spread of disease, and to educate citizens" (Cranz \& Boland, 2004, p. 103). During the mid- $20^{\text {th }}$ century, parks became recognized primarily as sites of recreation, and stadiums and asphalt basketball courts were added liberally. By the 1960s, some public officials looked to parks to help resolve racial tensions and stop riots, focusing on open space as places of participation, revitalization, and social control (Cranz, 1982). But as with Olmstead Sr.'s hope that the mere presence of diverse people together in green spaces would add to the "pleasure of others", these efforts to reduce racial tensions lacked strong theoretical foundations and empirical evidence.

\subsection{Social Interaction and Intergroup Contact}

Urban parks have been associated with positive mental health benefits distinct from any physical health benefits such as increased physical activity (Sturm \& Cohen, 2014; Sugiyama, Leslie, Giles-Corti, \& Owen, 2008). Public health studies have shown a correlation between access and use of parks or open space and lower resting heart rate, reduced stress, and better mental health across age groups (Balseviciene et al., 2014; Grazuleviciene et al., 2014; Song et al., 2014). Much of the literature linking use of public spaces to health focused on the restorative nature of green settings and contact with nature (Francis, Wood, Knuiman, \& Giles-Corti, 2012; Kaplan \& Kaplan, 1989; Ulrich, 1984). Less research has focused on social interaction as the important mechanism, with parks and open space facilitating the development of supportive relationships (Berkman 
\& Glass, 2000; Cattell, Dines, Gesler, \& Curtis Mingling, 2008; Francis, Giles-Corti, Wood, \& Knuiman, 2012; Francis, Wood et al., 2012; Putnam, 2000). Public health research has considered racial/ethnic variation in park use (Derose, Han, Williamson, Cohen, \& RAND Corporation, 2015), but these studies do not consider whether people across race/ethnicity are interacting in parks. Contemporary urban greening literature also addresses social cohesion as a possible link between urban green space and human health. Here, research suggests that community green spaces that do not impede ground level views can reduce antisocial outcomes such as crime and household aggression (Donovan \& Prestemon, 2012; Kuo \& Sullivan, 2001), and that this may be due to signalling social ties, increasing informal surveillance, or mitigating mental fatigue (Jacobs, 1961; Kaplan, 1995; Newman, 1972; Wilson \& Kelling, 1982). Some studies also suggest that community green spaces can promote pro-social outcomes such as greater neighbourhood social ties, more face-toface contact, larger groupings of people, and increased interaction between youth and adults (Coley, Kuo, \& Sullivan, 1997; Kuo, Bacaoica, \& Sullivan, 1998; Sullivan, Kuo, \& DePooter, 2004). As with the earlier park movements, these contemporary discussions lack specificity about how parks and other forms of green space promote prosocial behaviour and social cohesion.

We turn, then, to the fields of leisure studies and environmental and social psychology where researchers have focused on the social nature of parks and other natural environments and investigated the implications of these social interactions for different populations across location, age groups, income levels, race/ethnicity, and immigrant status. Rapid urbanization, car ownership, increased employment rates for women, and increased importance of social media and electronic communication has led to the weakening of neighbourhood ties in urban areas (Kazmierczak, 2013). Beyond the feelings of security and belonging, neighbourhood social ties may be important to dissemination of information and mutual aid (Kazmierczak, 2013; Kuo, Sullivan, Coley, \& Brunson, 1998). Public spaces including neighbourhood parks can facilitate development of meaningful social ties. Kazmierczak (2013) found that even in inner-city neighbourhoods with high levels of deprivation, parks served as sites for initiating and strengthening social ties for those who visit parks regularly. These "everyday places" can contribute to a general sense of well-being by providing a relief from daily routines and stress at home through social interactions that may be as simple as nods and smiles (Cattell et al., 2008).

A number of studies have investigated the positive impact of social interactions in parks and other public spaces on facilitating acculturation and adaptation for immigrant groups (Peters, Elands, \& Buijs, 2010; Stodolska, Peters, \& Horolets, 2016). Main (2013) investigates the meaning of urban parks for immigrants using the concepts of place attachment and place identity, finding that natural and social elements of urban parks can pro- vide important reminders of immigrants' sending communities. Seeland, Dübendorfer and Hansmann (2009) describe how public urban green spaces can help foster social inclusion as immigrant youths have opportunities to build cross-cultural social capital through sports and other forms of active play.

Several of these studies emphasize the importance of aesthetic qualities and design, arguing that parks need to be attractive and well-maintained, and have adequate seating and shade in order to maximize their positive impacts (Francis, Wood et al., 2012; Kazmierczak, 2013; Peters et al., 2010). Preferences regarding park attributes may also differ by gender and ethnicity (Ho et al., 2005). Many studies also note that cross-cultural, interracial, and inter-ethnic interactions can lead to social tension, particularly in public spaces that may be racially demarcated and where there may be conflict over use of space for activities such as sporting events and vending (Lee \& Scott, 2013; Main, 2013; Peters et al., 2010). Parks must be understood as operating within a historical, socio-ecological, and political-economic context, making them "ideologically charged" and often "ethnoracially inscribed" spaces (Byrne \& Wolch, 2009) that can be experienced as both barriers (Byrne, 2012) or "green walls" (Solecki \& Welch, 1995), discouraging access, for racial/ethnic minorities, as well as "green magnets" that potentially improve interracial relations (Gobster, 1998). In other words, simply facilitating social interactions across groups is not enough to insure positive benefits for immigrants or racial/ethnic minorities.

Allport's intergroup contact theory (1954) offers a framework for understanding the conditions under which interracial and inter-ethnic social interactions, such as those that may occur in urban neighbourhood parks, can have positive impact on people on both sides of the interaction by reducing bias and conflict. These conditions include people across groups experiencing equal group status within the encounter, common goals, an experience of intergroup cooperation, support from authority and "friendship potential" (Brown \& Hewstone, 2005; Dovidio, Gaertner, \& Kawakami, 2003; Pettigrew, 1998). Recent research has also considered the role of expectations; when individuals across groups approach intergroup contact with positive expectations, the interactions are more likely to generate positive outgroup attitudes (Deegan, Hehman, Gaertner, \& Dovidio, 2015).

Researchers across disciplines have tested intergroup contact theory in the context of military, worksites, schools, neighbourhoods, housing complexes, and religious congregational settings. Longitudinal studies (Binder et al., 2009; Christ et al., 2010; Eller \& Abrams, 2004; Levin, van Laar, \& Sidanius, 2003) and metaanalyses (Hodson \& Hewstone, 2013; Pettigrew \& Tropp, 2006) demonstrate consistent and relatively large and positive effects of intergroup contact on prejudice and intergroup conflict across age groups, settings, and countries (Pettigrew, 2016). These positive effects of intergroup contact are not limited to the group members 
who are directly involved in the interaction but extend to the larger group by impacting norms (Christ et al., 2014; Pettigrew, 2016). Fewer studies have applied intergroup contact theory to urban public places such as neighbourhood parks. One study by Lee and Scott (2013) investigated the experience of Korean American males ages 19-36 playing pickup basketball or soccer. Most participants indicated that interracial contact through recreational sports contributed to harmonious interracial relations and that the optimal conditions of such contact as defined by intergroup theory need not be satisfied for positive contact to occur. They pointed, instead, to skill level and physical attributes of participants, length of contact, and climate within the recreational setting as key factors.

The Lee and Scott (2013) study, like other research in leisure studies focusing on social interactions in public parks, employed a qualitative research methodology (Cattell et al., 2008: Peters et al., 2010; Seeland et al., 2009; Stodolska et al., 2016). While in-depth interviews, ethnography, and focus groups are ideal for understanding the meanings people assign to interracial and interethnic interactions, they necessarily employ very small samples that limit their generalizability. Other studies have used surveys to capture information from residents about their interracial and inter-ethnic interactions in public parks and the meanings they assign those experiences (Ho et al., 2005; Maas et al., 2009; Main, 2013; Peters et al., 2010; Rios, Aiken, \& Zautra, 2012; Seeland, Dübendorfer, \& Hansmann, 2009). While these studies have larger samples, they rely on self-report about the frequency and conditions of interracial and inter-ethnic contact.

\subsection{Racism and Health Disparities}

Within public health literature, concern about the role of urban neighbourhood parks in racial health disparities has focused on lack of physical access to parks, disproportionate exposure to park disamenities, and racial disparities in park use by people of color (Abercrombie et al., 2008; Watson, Harris, Carlson, Dorm, \& Fulton, 2016; Weiss et al., 2011). The pathway linking parks and public health has focused on parks as sites for physical activity, not social interaction. Distinct from the extensive literature on parks, public health research has focused on numerous ways in which prejudice and institutional racism negatively impact health, particularly for Blacks/African Americans (Gee \& Ford, 2011; Gee, Walsemann, \& Brondolo, 2012; Jones, 2000; Krieger, 1999). Most research identifies stress, caused by the "accumulated insults arising from every-day and sometimes violent experiences of being treated as a second-class citizen" (Krieger, 1999, p. 332), as a critical link between racial discrimination and health. Recent research has also documented a connection between discrimination and increased risk-taking behaviours (Jamieson, Koslov, Nock, \& Mendes, 2013). While only one of many aspects of racism, interpersonal conflict and discrimination, or what Krieger (1999) calls "socially inflicted trauma", contributes to the lived experience-and negative health consequences- of racism. Krieger refers to "embodiment" as the way that discrimination "gets under the skin". (Krieger, 1999, 2016). Decreasing or eliminating racial prejudice and discrimination could, therefore, have positive health implications for Blacks/African Americans. Numerous studies, most of them published outside of public health, consider parks as sites of racial discrimination (Gobster, 1998, 2002; Rishbeth, 2001; West, 1989) but they do not link exposure to discrimination to racial health disparities.

\subsection{Public Health Measures of Park Use and Features}

Public health research has focused on the human health implications of parks primarily as sites for promoting physical activity (Brownson, Hoehner, Day, Forsyth, \& Sallis, 2009; Cohen et al., 2007; Jones \& Lachowycz, 2011; Kaczynski \& Henderson, 2008). While this body of research largely neglects the potential pathway linking parks and improved health through social cohesion and intergroup contact, it does offer important tools for measuring park conditions and activities that can be applied to research focused on these social pathways. Research on parks and physical activity has increasingly employed objective measures of human behaviour, through systematic observation, electronic devices such as accelerometers, heart-rate monitors, and global positioning systems (GPS), and systematic audits of built environment conditions (King, Glanz, \& Patrick, 2015; McKenzie, Cohen, Sehgal, Williamson, \& Golinelli, 2006; McKinnon, Reedy, Berrigan, \& Krebs-Smith, 2012). Specifically, studies have employed physical activity logs, GPS, accelerometers, and direct observation of physical activity on the way to (Evenson, Wen, Hillier, \& Cohen, 2013) and within parks (Kaczynski, Luke, Potwarka, \& Saelens, 2008; Quigg, Gray, Reeder, Holt, \& Waters, 2010) to document the public health value of these investments. These are promoted as objective measures of physical activity in response to the documented social desirability and recall bias of survey-based and other self-report measures of physical activity.

In summary, we draw on scholarship from planning and landscape architecture history, leisure studies, psychology and public health to focus attention on the importance of social interactions rather than only on physical activity. In connecting public health research on the negative health impacts of racial discrimination for Blacks/African Americans to Allport's theory of intergroup contact (1954), we identify a specific possible causal pathway that links positive interracial social interactions in neighbourhood parks to improved health for all groups.

Borrowing from the observation measures used for public health studies on physical activity in parks, we employ a method of systematic observation to identify 
what combination of people, across age, gender and race, are present in the same section of urban neighbourhood parks across five cities as a first step in understanding the conditions under which interracial contact is most likely to occur. By employing quantitative methods to analyse a large sample of observations, we offer a complement to the more nuanced qualitative research in order to identify patterns across multiple cities and parks.

In this study, we address the following research questions: (1) How frequently are people across racial groups present in the same section of parks at the same time? (2) What are the characteristics of park areas and park activities that correlate with the co-presence of park users across racial groups? And (3) What neighbourhood characteristics in which parks are located are correlated with the co-presence of park users across racial groups? We use our results to highlight they ways that urban planners and public health professionals can work deliberately to design and program neighbourhood parks to maximize their public health impact. Our analysis of who is coming into contact in parks has important implications for understanding and, potentially, improving interracial and interethnic relations. This is especially timely in light of the ethnic confrontation that is entangled with contemporary globalization and urbanization around the world, and within the United States, the "Age of Ferguson" and Black Lives Matter movement (Derickson, 2016).

\section{Research Methods}

The System for Observing Play and Recreation in the Community (SOPARC) is a validated direct observation tool for assessing use of park and recreation areas, including park users' physical activity levels, gender, activity types, and estimated age and ethnicity groupings (McKenzie et al., 2006). SOPARC has been used to show variability in physical activity levels across park users by age, gender, race/ethnicity (Besenyi, Kaczynski, Wilhelm Stanis, \& Vaughan, 2013; Reed \& Hooker, 2012; Reed, Hooker, Muthukrishnan, \& Hutto, 2011; Reed, Price, Grost, \& Mantinan, 2012), park areas (Besenyi et al., 2013), parks, cities, and seasons (Chow, McKenzie, \& Sit, 2016; Cohen et al., 2013; Ward et al., 2014), urban versus rural settings (Shores \& West, 2010) and neighbourhoods based on walkability, racial composition and income (Cohen et al., 2013; Van Dyck et al., 2013; Ward et al., 2014). Previous studies have used SOPARC data on gender, age, and race/ethnicity to document disparities across groups in the use of parks and physical activity levels (Evenson, Jones, Holliday, Cohen, \& McKenzie, 2016; Kaczynski, Wilhelm Stanis, Hastmann, \& Besenyi, 2011) but not to investigate the combinations of people who are co-present in parks.

Observations were made using SOPARC at 31 neighbourhood parks across five different US cities during the spring, summer and fall between 2008 and 2010. Researchers from Albuquerque, NM, Columbus, $\mathrm{OH}$, Chapel Hill/Durham, NC, and Philadelphia, PA selected six parks each and researchers from Los Angeles CA selected seven neighbourhood parks from areas with different racial/ethnic and income composition. Some but not all parks included a recreation center and full-time staff. Trained staff observed all areas of each park at four randomly-selected 1-hour intervals between 7am and $8 \mathrm{pm}$ on two randomly selected weekdays and two randomly-selected weekend days over at least 3 seasons of the year (Cohen et al., 2011). The time of day and day of the week were recorded for each observation. Two observers worked together to document the type of activity and each person's physical activity (sedentary, walking, vigorous), gender, age group (child, adolescent, adult, senior), and race/ethnicity (Latino, African American, White, and other). Reliability checks with a third independent observer were conducted to insure that the procedure had good reproducibility (Ward et al., 2014). Prior studies indicate that SOPARC can assess these measures reliably (Cohen et al., 2007).

\subsection{Characteristics of Park Target Areas}

Overall park size was calculated as a continuous variable (in acres). Each park was mapped and divided into discrete target areas to make observations more manageable. The type of facilities present (i.e., playground, baseball field, basketball court, indoor weight room) were documented for each target area. Two staff rotated around the park, systematically observing each target area and identifying whether it was physically accessible (i.e., not locked), empty, organized (scheduled sporting event or exercise class), and supervised by park staff, coach, volunteer, or teacher.

\subsection{Characteristics of Park Users}

Observations were coded based on the total number of people present, whether at least one male and one female was present, only males were present, or only females were present and whether any children, teens, adults or seniors were present. Based on data collected in the field, all observations were later coded as interracial or not based on whether at least one white and one non-white person were present in the same target area at the same time. Interracial was defined exclusively as the simultaneous presence of someone white and someone non-white in the same target area. We chose to operationalize interracial this way because whites represented the largest (Columbus and Chapel Hill/Durham) or second largest (Albuquerque, Los Angeles, and Philadelphia) demographic group in all of the cities. Also, historically racial/ethnic conflict in the United States has been defined largely in the context of white privilege and white supremacy that categorizes all nonwhites as "other" (Mills, 1997). Research using SOPARC has consistently shown high levels of inter-rater reliability in regard to the total number of people observed, age, gender, and race/ethnicity (Evenson et al., 2016). 


\subsection{Characteristics of Activities}

Staff identified the number of males and number of females being sedentary or standing without moving (heretofore referred to as sedentary), moderately active (such as walking), or vigorously active. SOPARC has also been shown to have high levels of inter-rater reliability for physical activity levels (Evenson et al., 2016). They also identified the primary activity for the females and males inside the target area (i.e., sitting, running, swinging) as well as whether there were any spectators present. All observations were later coded based on whether the primary activity involved a team sport, a playground activity, sedentary activity, such as sitting, standing, picnicking, reading, or lying down, moderate activity such as walking, or whether anyone within the target area was being vigorously active or not.

\subsection{Characteristics of Park Neighbourhoods}

The neighbourhood racial/ethnic and income characteristics of each park were determined using 2000 US Census data for block groups with centroids within half a mile of park boundaries for parks in all cities other than Chapel Hill/Durham where block groups with centroids within 0.8 mile were used because of much lower population densities. The population density and the percent of neighbourhood residents who were white, Black/African American, and Hispanic/Latino and living in poverty were determined for all parks. Neighbourhoods were then identified as having a high interracial mix (no racial/ethnic group made up more than $50 \%$ of population) or medium interracial mix (no racial/ethnic group made up more than $70 \%$ of the population), and as having a high poverty (poverty rate greater than $25 \%$ or not) or low poverty (poverty rate less than $15 \%$ or not). Poverty rate was measured as a continuous variable for the GEE model.

\subsection{Statistical Analysis}

Descriptive statistics were generated to compare the timing of observations, characteristics pf park target areas, and characteristics of park activities across cities and neighbourhoods. Generalized Estimating Equations (GEE) were used to analyse the SOPARC data. GEE models are appropriate given the clustered nature of the sample (i.e., multiple target areas with park) and multiple observations taking place on the same day in the same park in the same city.

This research protocol was approved by the Institutional Review Boards of the University of Pennsylvania, RAND Corporation, The Ohio State University, University of North Carolina, and Behavioral Health Research Center of the Southwest/PIRE.

\section{Results}

Of the 43,706 observations made across the 31 parks, only $7,352(16.8 \%)$ included two or more people present in the same target area at the same time. Less than onethird of these observations (31.6\%) included at least one white and one non-white person. The frequently of observations of interracial groups varied by city, with the highest rate (40.5\%) in Chapel Hill and the lowest (23.6\%) in Philadelphia. There were also significant differences across cities in the age and gender of park participants and the amount of sedentary behavior, walking, vigorous activity, and supervised activity (see Table 1).

Table 2 shows that many of these same variables varied based on the characteristics of neighbourhoods in which the parks were located. The co-presence of park users across racial groups was more likely to occur in neighborhoods with a high interracial mix (39.6\%) relative to neighbourhoods with a moderate interracial mix $(28.8 \%)$ and in both low poverty (26.2\%) and highpoverty (16.3\%) areas relative to all areas (31.6\%). Differences in who was observed using parks across gender and age-groups was more pronounced based on neighbourhood racial/ethnic and income composition. Female park users were nearly twice as likely to be observed in a target area when no males were present in lowpoverty areas $(27.3 \%)$ than high-poverty areas $(13.4 \%)$ while male park users were more likely to be observed in a target area with no females present in low-poverty (46.7\%) than high-poverty $(30.1 \%)$ areas. Parks in highpoverty areas were less likely to have any adults (64.3\%) or any seniors $(4.0 \%)$ present than areas overall $(80.0 \%$ and $11.2 \%$, respectively).

Through the multivariate GEE analysis (Table 3), a number of characteristics of the park users, their activities, and park neighbourhood were significantly associated with the co-presence of park users across racial groups. If children or teens were present or both men and women were present, there was significantly greater likelihood than if only adults, only men, or women were present $(\log$ odds ratio $=.18, .51$, and $.62, p=.048, .0001$, and .0001 , respectively). In terms of what park users were doing, supervised activities were significantly more likely than non-supervised activities (log odds ratio $=.79$, $\mathrm{p}=.0001$ ) and vigorous activities (log odds ratio $=.42$, $\mathrm{p}=.0001$ ) were significantly more likely than moderate or sedentary activities to involve park users across racial groups. Only 634 of our 7352 observations (8.6\%) involved supervised activities, but 358 of these (56.5\%) involved the co-presence of people across racial groups and $351(55.4 \%)$ involved at least one person being vigorously active. Gyms, baseball fields, lawns, and tennis courts were most likely to be the sites of supervised activities that included park users across racial groups and vigorous physical activity. Basketball courts were the most likely to be supervised and involve vigorous physical activity, but they were less likely than gyms, baseball fields, and tennis court to have people across racial groups present at the same time.

Neighbourhood characteristics showed some interesting associations, as well. Neighbourhoods with high and medium racial mix were significantly more likely to 
Table 1. Descriptive statistics by city for sample of park observations ( $\left.\mathrm{N}=7352^{*}\right)$.

\begin{tabular}{|c|c|c|c|c|c|c|}
\hline & $\begin{array}{l}\text { All cities } \\
N=7352\end{array}$ & $\begin{array}{l}\text { Albuquerque } \\
\mathrm{N}=1141\end{array}$ & $\begin{array}{l}\text { Chapel Hill/ } \\
\text { Durham NC } \\
N=1664\end{array}$ & $\begin{array}{l}\text { Columbus } \mathrm{OH} \\
\mathrm{N}=826\end{array}$ & $\begin{array}{l}\text { Los Angeles } \\
N=2193\end{array}$ & $\begin{array}{l}\text { Philadelphia } \\
\mathrm{N}=1528\end{array}$ \\
\hline \multicolumn{7}{|c|}{ Timing of Observations } \\
\hline Weekend & 3509 (47.7\%) & $628(55.0 \%)$ & $1042(62.6 \%)$ & $403(48.8 \%)$ & $733(33.4 \%)$ & 703 (46.0\%) \\
\hline Spring & $1777(24.2 \%)$ & $458(40.1 \%)$ & $583(35.0 \%)$ & $233(28.2 \%)$ & $0 * *$ & 503 (32.9\%) \\
\hline Summer & 3085 (42.0\%) & $353(30.9 \%)$ & $459(27.6 \%)$ & $330(40.0 \%)$ & 1339 (61.1\%) & $604(39.5 \%)$ \\
\hline Fall & $2248(30.6 \%)$ & $330(28.9 \%)$ & $622(37.4 \%)$ & $263(31.8 \%)$ & $612(27.9 \%)$ & $421(27.6 \%)$ \\
\hline \multicolumn{7}{|c|}{ Characteristics of Target Areas } \\
\hline Playground & $897(12.2 \%)$ & $145(12.7 \%)$ & $192(11.5 \%)$ & $129(15.6 \%)$ & $209(9.5 \%)$ & $222(14.5 \%)$ \\
\hline Supervised & $634(8.6 \%)$ & $30(2.6 \%)$ & $193(11.6 \%)$ & $113(13.7 \%)$ & $229(10.4 \%)$ & $69(4.5 \%)$ \\
\hline Team Sport & $885(12 \%)$ & $108(9.5 \%)$ & 157 (9.4\%) & $83(10.0 \%)$ & $306(14.0 \%)$ & $231(15.1 \%)$ \\
\hline \multicolumn{7}{|c|}{ Characteristics of Park Activities and People in Target Areas } \\
\hline $\begin{array}{l}\text { Interracial } \\
\text { Physical Activity }\end{array}$ & \multicolumn{5}{|c|}{ Physical Activity } & $360(23.6 \%)$ \\
\hline Sedentary & $2353(32.0 \%)$ & $367(32.2 \%)$ & $313(18.8 \%)$ & $172(20.8 \%)$ & $946(43.1 \%)$ & $555(36.3 \%)$ \\
\hline Walking & $998(13.6 \%)$ & $223(19.5 \%)$ & $294(17.7 \%)$ & $41(5.0 \%)$ & $288(13.1 \%)$ & $152(9.9 \%)$ \\
\hline Vigorous & $2654(36.1 \%)$ & $285(25.0 \%)$ & $761(45.7 \%)$ & $323(39.1 \%)$ & $767(35.0 \%)$ & $518(33.9 \%)$ \\
\hline \multicolumn{7}{|l|}{ Gender } \\
\hline Male and Female & 3549 (59.5\%) & $285(44.0 \%)$ & $761(65.7 \%)$ & $323(61.9 \%)$ & $767(47.5 \%)$ & $518(45.9 \%)$ \\
\hline Female Only & $890(14.9 \%)$ & $151(23.3 \%)$ & 143 (12.3\%) & $68(13.0 \%)$ & $261(16.2 \%)$ & 267 (23.6\%) \\
\hline Male Only & $1526(25.6 \%)$ & $211(32.6 \%)$ & 254 (21.9\%) & 131 (25.1\%) & $586(36.3 \%)$ & $344(30.5 \%)$ \\
\hline \multicolumn{7}{|l|}{ Age Group } \\
\hline Any Children & 4060 (55.2\%) & 609 (53.4\%) & 947 (56.9\%) & $590(71.4 \%)$ & 1115 (50.8\%) & 799 (52.3\%) \\
\hline Any Teens & 1791 (24.4\%) & 261 (22.9\%) & $284(17.1 \%)$ & $271(32.8 \%)$ & 555 (25.3\%) & $420(27.5 \%)$ \\
\hline Any Adults & 5885 (80.0\%) & $922(80.8 \%)$ & 1491 (89.6\%) & $559(67.7 \%)$ & 1924 (87.7\%) & 989 (64.7\%) \\
\hline Any Seniors & $820(11.2 \%)$ & $163(14.3 \%)$ & $240(14.4 \%)$ & 36 (4.4\%) & 333 (15.2\%) & $48(3.1 \%)$ \\
\hline
\end{tabular}

* This represents the subset of all observations where two or more people were present in the same park target area at the same time.

** No observations were conducted during the spring in Los Angeles.

have park users across racial group co-present (log odds ratio $=.72$ and $.71, p=.009$ and .004 , respectively) than racially homogenous neighbourhoods in their community parks. Poverty level of a neighbourhood had a significant and complex relation, through the interaction with the percentage of white population in the neighbourhood. In a white-majority neighbourhood (e.g., \%white = $50 \%)$, poverty level was not significantly associated with interracial grouping. In a neighbourhood with a relatively low percent of white residents (e.g., \%white $=10 \%$ ), poverty level had a significant and negative association ( $\log$ odds ratio $=-.05, p=.01)$. On the other hand, the percentage of white population always had a significant and positive association regardless of the local poverty level. For example, in a relatively high-income neighbourhood with $10 \%$ households in poverty, every percentage point of white population had an estimated log odds ratio of .02 ( $p=.0004)$ for interracial grouping. In a relatively low-income neighbourhood with $30 \%$ households in poverty, the log odds ratio for interracial grouping is $.04(p=.0001)$. Differences among cities were not significant in the multivariate model when controlling for the percent poverty and racial composition of the area around the park, suggesting the lack of unobserved confounders for the outcome of interest besides poverty, racial/ethnicity structure, and their interaction.

\section{Discussion}

Extensive observation across five cities, three seasons, and 31 neighborhoods reveal that only a fraction of target areas in neighbourhood parks are populated by two or more people at any given time, and in less than onethird of the populated areas those park users represented different racial groups, defined as at least one white and one non-white person. Still, we identified 2,123 instances where people of different racial groups were copresent, suggesting that neighbourhood parks can potentially serve as places that promote intergroup contact. While our results speak only to co-presence, and not necessarily "contact" as described by Allport, they provide some quantitative evidence that applying interracial contact theory to understanding psychosocial pathways between park use and human health is worthwhile. Further- 
Table 2. Descriptive statistics by area racial/ethnic and income composition for sample of park observations.

\begin{tabular}{|c|c|c|c|c|}
\hline & \multicolumn{2}{|c|}{ Interacial mix } & \multicolumn{2}{|c|}{ Poverty } \\
\hline & $\begin{array}{l}\text { Moderate interracial } \\
\mathrm{N}=2,420\end{array}$ & $\begin{array}{l}\text { High interracial } \\
N=1,183\end{array}$ & $\begin{array}{l}\text { Low poverty } \\
N=3266\end{array}$ & $\begin{array}{l}\text { High poverty } \\
N=1269\end{array}$ \\
\hline Weekend & 1242 (51.3\%) & 399 (33.7\%) & 1610 (49.3\%) & 515 (40.6\%) \\
\hline Spring & $743(30.7 \%)$ & 175 (14.8\%) & $573(17.5 \%)$ & $288(22.7 \%)$ \\
\hline Summer & 1110 (45.9\%) & 840 (71.0\%) & 947 (29.0\%) & 646 (50.9\%) \\
\hline Fall & 567 (23.4\%) & $97(8.2 \%)$ & 1643 (50.3\%) & 335 (26.4\%) \\
\hline Playground & 335 (13.8\%) & $169(14.3 \%)$ & 315 (9.6\%) & $160(12.6 \%)$ \\
\hline Supervised & $98(4.0 \%)$ & $85(7.2 \%)$ & $254(7.8 \%)$ & 101 (8.0\%) \\
\hline Team Sport & 235 (9.7\%) & $187(15.8 \%)$ & $628(19.2 \%)$ & $238(18.8 \%)$ \\
\hline Interracial & $698(28.8 \%)$ & 469 (39.6\%) & $856(26.2 \%)$ & 207 (16.3\%) \\
\hline \multicolumn{5}{|l|}{ Physical Activity } \\
\hline Sedentary & 891 (36.8\%) & $524(44.3 \%)$ & $921(28.2 \%)$ & 458 (36.1\%) \\
\hline Walking & $296(12.2 \%)$ & 149 (12.6\%) & 484 (14.8\%) & $108(8.5 \%)$ \\
\hline Vigorous & 706 (29.2\%) & 396 (33.5\%) & 1207 (37.0\%) & 427 (33.6\%) \\
\hline \multicolumn{5}{|l|}{ Gender } \\
\hline Male And Female & 1239 (62.1\%) & 659 (59.1\%) & 452 (15.8\%) & 452 (45.0\%) \\
\hline Female Only & $320(16.0 \%)$ & $153(13.7 \%)$ & 890 (31.0\%) & 170 (16.9\%) \\
\hline Male Only & $439(22.0 \%)$ & $303(27.2 \%)$ & 1526 (53.2\%) & 382 (38.0\%) \\
\hline \multicolumn{5}{|l|}{ Age Group } \\
\hline Any Children & 1325 (54.8\%) & 649 (54.9\%) & 1428 (43.7\%) & 665 (52.4\%) \\
\hline Any Teens & $570(23.6 \%)$ & 349 (29.5\%) & $694(21.2 \%)$ & 501 (39.5\%) \\
\hline Any Adults & 1875 (77.5\%) & 997 (84.3\%) & 2551 (78.1\%) & $816(64.3 \%)$ \\
\hline Any Seniors & 231 (9.5\%) & 123 (10.4\%) & 369 (11.3\%) & $510(4.0 \%)$ \\
\hline
\end{tabular}

more, our research shows that certain parks, park users, and neighbourhood characteristics make the co-presence of park users across racial groups-and potentially interracial contact-more or less likely. Some of these, like neighbourhood racial/ethnic and income composition, cannot be changed easily, while others, such as whether males and females and children are present at the same time or activities are supervised, are modifiable. To understand the impact of these empirical results on intergroup contact, we turn first to the modifiable factors where there are the greatest opportunities for intervention.

The factor that can potentially be modified most easily is the supervision of specific activities in parks. Supervision might take the form of a coach, referee, park staff person, or an adult who represents some level of authority and provides a certain amount of oversight. While having full-time staff at neighbourhood parks may be financially unrealistic in all communities, volunteers including summer high school and college interns, graduate students and faculty (Han et al., 2015), City Year and VISTA (Volunteers in Service to America) volunteers, or retirees may present low- to no-cost strategies for organizing and supervising activities in neighbourhood parks. This could be modelled after supervised recess at school through programs such as Playworks (Beyler, Bleeker, James-Burdamy, Fortson, \& Benjamin, 2014).

Unlike the supervision of park activities, neighbourhood racial/ethnic and income composition-which also holds a considerable influence on whether people across racial groups are co-present-are not easily modifiable. The neighbourhood parks with the most observations including people across racial groups were located in areas of relatively low poverty and majority but not exclusively white populations. The one exception was a park in Los Angeles that had a moderate poverty rate $(18.3 \%)$ and no majority racial/ethnic population but significant white and Latino populations. The neighbourhood parks with the highest poverty rates and largest Black/African American populations were least likely to have people across racial groups co-present. This does not preclude interventions focused on increasing the amount of supervised activities in neighbourhood parks; having supervised activities makes vigorous physical activity more likely even when interracial contact is unlikely. But deliberate efforts to promote interracial contact are most likely to be successful in areas of low and moderate poverty and with at least some racial/ethnic mix. That parks in areas with even non-majority Black/African-American populations are unlikely to have much interracial contact demonstrates the high levels of white prejudice that need to be reversed. These results demonstrate yet another way that the persistence and co-occurrence of racial/ethnic and income segregation at the neighbourhood level can reinforce health disparities by making intergroup contact in parks unlikely (Krieger, 2016).

The strengths of this research include the large sample of observations from neighbourhood parks across five different cities and different racial/ethnic and income com- 
Table 3. Analysis of GEE parameter estimates for interracial contact.*

\begin{tabular}{|c|c|c|c|c|c|c|}
\hline & Estimate & SE & \multicolumn{2}{|c|}{ 95\% Confidence Interval } & Z-value & p-value \\
\hline \multicolumn{7}{|l|}{ State } \\
\hline CA & 0.198 & 0.3135 & -0.4165 & 0.8126 & 0.63 & 0.5277 \\
\hline NC & 0.3877 & 0.2934 & -0.1873 & 0.9626 & 1.32 & 0.1864 \\
\hline NM & 0.3121 & 0.3101 & -0.2957 & 0.9198 & 1.01 & 0.3143 \\
\hline $\mathrm{OH}$ & 0.3452 & 0.3265 & -0.2947 & 0.9851 & 1.06 & 0.2903 \\
\hline PA & referent & referent & referent & referent & referent & referent \\
\hline \multicolumn{7}{|c|}{ Timing of observation } \\
\hline Weekend & -0.1982 & 0.0996 & -0.3935 & -0.0029 & -1.99 & 0.0466 \\
\hline Spring & -0.0515 & 0.0875 & -0.2229 & 0.1199 & -0.59 & 0.5559 \\
\hline Summer & -0.0835 & 0.0641 & -0.2091 & 0.0421 & -1.3 & 0.1928 \\
\hline Fall & referent & referent & referent & referent & referent & referent \\
\hline \multicolumn{7}{|c|}{ Characteristics of Park and Target Areas } \\
\hline Park Size (Acres) & 0.0015 & 0.0079 & -0.014 & 0.0171 & 0.19 & 0.8464 \\
\hline Playground & -0.1649 & 0.1349 & -0.4293 & 0.0995 & -1.22 & 0.2216 \\
\hline Team Sport & 0.1228 & 0.0983 & -0.0698 & 0.3154 & 1.25 & 0.2115 \\
\hline Supervised & 0.7927 & 0.1157 & 0.5659 & 1.0196 & 6.85 & $<.0001$ \\
\hline \multicolumn{7}{|c|}{ Characteristics of Park Activities and People in Target Areas } \\
\hline \multicolumn{7}{|l|}{ Physical Activity } \\
\hline Sedentary & -0.0175 & 0.0647 & -0.1443 & 0.1093 & -0.27 & 0.787 \\
\hline Walking & -0.1522 & 0.1189 & -0.3851 & 0.0808 & -1.28 & 0.2005 \\
\hline Vigorous & 0.4166 & 0.0641 & 0.2909 & 0.5424 & 6.5 & $<.0001$ \\
\hline \multicolumn{7}{|l|}{ Gender } \\
\hline Male and Female & 0.6184 & 0.0749 & 0.4715 & 0.7652 & 8.25 & $<.0001$ \\
\hline Female Only & -0.1128 & 0.1348 & -0.377 & 0.1514 & -0.84 & 0.4027 \\
\hline Male Only & referent & referent & referent & referent & referent & referent \\
\hline \multicolumn{7}{|l|}{ Age Group } \\
\hline Any Children & 0.1836 & 0.0928 & 0.0017 & 0.3655 & 1.98 & 0.0479 \\
\hline Any Teens & 0.514 & 0.0777 & 0.3617 & 0.6663 & 6.61 & $<.0001$ \\
\hline \multicolumn{7}{|c|}{ Characteristics of Park Neighborhood } \\
\hline Percent Poverty & -0.0573 & 0.0224 & -0.1011 & -0.0134 & -2.56 & 0.0104 \\
\hline Percent White & 0.0135 & 0.0094 & -0.005 & 0.032 & 1.44 & 0.1513 \\
\hline \%Pov * \%White & 0.0009 & 0.0004 & 0.0001 & 0.0016 & 2.33 & 0.02 \\
\hline High Racial Mix & 0.7183 & 0.2751 & 0.1792 & 1.2575 & 2.61 & 0.009 \\
\hline Mod Racial Mix & 0.7129 & 0.248 & 0.2268 & 1.199 & 2.87 & 0.004 \\
\hline
\end{tabular}

*Statistical model adjusts for everything listed in the table in addition to accounting for the correlation of multiple target areas within parks.

position. No previous published study has analysed such a large number of observations as an objective measure of the co-presence of racial groups. While the parks were not selected at random, the days of the weeks and times of the day when observations were conducted were selected randomly, and observations were conducted over three seasons, depending upon the city, allowing for some generalizability of findings across US cities.

The limitations of this analysis are important to acknowledge. Operationally defining interracial as involving white and non-white park users likely underestimates the true amount of interracial activity, which could include co-presence in park areas among non- white groups such as Asians, Blacks/African Americans, and Latinos that could also have important health implications. This binary approach to defining interracial also masks important historical differences in how Hispanic/Latinos and Asians are perceived and treated by whites as forms of discrimination between minority groups (Fernandez \& Witt, 2013; Sharaievska, Stodolska, Shinew, \& Kim, 2010). Using SOPARC, we are able to identify areas where people across racial groups are copresent, but we cannot assume this involved contact, as described by Allport. In reality, people occupying the same general area within a park could be participating in separate activities that involve no interaction. Also, our 
analysis treats individual park target areas as the unit of analysis without accounting for their size.

\section{Implications for Future Research}

Research on intergroup contact frequently emphasizes the conditions that facilitate positive effects, such as the presence of authority to support both groups. We may be able to infer that supervision of park activities constitutes this authority, but we know nothing about the nature of those interactions-including the amount of civility, engagement, friendship, or conflict-through observations using the conventional SOPARC measure. Further research is needed to investigate the nature of the interactions among people across racial groups and their impact on individual attitudes and behaviours. Adaptations to SOPARC might include new considerations of the verbal language, body language, tone of voice, eye contact, physical contact, and other characteristics of the interaction among park users. Or, on the model of Cohen et al. (2016), separate measures of intoxication, smoking, fighting, or groups of people who were intimidating others within parks might be used in conjunction with SOPARC observations to measure conflict and potentially negative interactions. Existing measures of segregation might also be applied to the spatial configuration of park users across race/ethnicity, on the model of Echols, Solomon and Graham (2014) study of seating patterns in a school cafeteria using measures of exposure (potential for interaction among people across groups) and entropy (how evenly people across group are spread out over a space).

This study calls on researchers across disciplines to consider more broadly the contributions of parks to public health beyond physical activity and the psychosocial benefits of exposure to nature. Urban parks were purposefully designed in the $19^{\text {th }}$ Century with high expectations and democratic ideals, even if they may not have been intended to challenge white prejudice and institutional racism. The potential for neighbourhood parks and other outdoor, green public spaces to promote interracial contact represents an important and underappreciated pathway linking urban design and human health. Urban planning must meet this mandate for realizing the promise of neighbourhood parks by more carefully theorizing, designing, maintaining and then activating these public spaces to achieve equity and health.

\section{Acknowledgements}

This study was funded by the National Institutes of Health (NIH), National Heart Lung and Blood Institute \# R01HL092569. The content is solely the responsibility of the authors and does not necessarily represent the official views of the NIH.

\section{Conflict of Interests}

The authors declare no conflict of interests.

\section{References}

Abercrombie, L. C., Sallis, J. F., Conway, T. L., Frank, L. D., Saelens, B. E., \& Chapman, J. E. (2008). Income and racial disparities in access to public parks and private recreation facilities. American Journal of Preventive Medicine, 34(1), 9-15.

Allport, G. W. (1954). The nature of prejudice. Reading: Addison-Wesley.

Angel, S. (2012). Planet of cities. Cambridge, MA: Lincoln Institute of Land Policy.

Balseviciene, B., Sinkariova, L., Grazuleviciene, R., Andrusaityte, S., Uzdanaviciute, I., Dedele, A., \& Nieuwenhuijsen, M. J. (2014). Impact of residential greenness on preschool children's emotional and behavioral problems. International Journal of Environmental Research and Public Health, 11(7), 6757-6770.

Besenyi, G. M., Kaczynski, A. T., Wilhelm Stanis, S. A., \& Vaughan, K. B. (2013). Demographic variations in observed energy expenditure across park activity areas. Preventive Medicine, 56(1), 79-81.

Beyler, N., Bleeker, M., James-Burdamy, S., Fortson, J., \& Benjamin, M. (2014). The impact of playworks on students' physical activity during recess: Findings from a randomized control trial. Preventive Medicine, 69, S20-S26.

Binder, J., Zagefka, H., Brown, R., Funke, F., Kessler, T., Mummendey, A., Leyens, J.-P. (2009). Does contact reduce prejudice or does prejudice reduce contact? A longitudinal test of the contact hypothesis amongst majority and minority groups in three European countries. Journal of Personality and Social Psychology, 96(4), 843-856.

Brown, R., \& Hewstone, M. (2005). An integrative theory of intergroup contact. Advances in Experimental Social Psychology, 37, 255-343.

Brownson, R. C., Hoehner, C. M., Day, K., Forsyth, A., \& Sallis, J. F. (2009). Measuring the built environment for physical activity: state of the science. American Journal of Preventive Medicine, 36(4), S99-S123.

Byrne, J. (2012). When green is White: The cultural politics of race, nature and social exclusion in a Los Angeles urban national park. Geoforum, 43, 595-611.

Byrne, J., \& Wolch, J. (2009). Nature, race, and parks: Past research and future directions for geographic research. Progress in Human Geography, 33(6), 743-765.

Cattell, V., Dines, N., Gesler, W., \& Curtis Mingling, S. (2008). Mingling, observing, and lingering: Everyday public spaces and their implications for well-being and social relations. Health \& Place, 14(3), 544-561.

Chow, B. C., McKenzie, T. L., \& Sit, C. H. P. (2016) Public parks in Hong Kong: Characteristics of physical activity areas and their users. International Journal of Environmental Research and Public Health, 13(7), 639.

Christ, O., Hewstone, M., Tausch, N., Wagner, U., Voci, A., Hughes, J., \& Cairns, E. (2010). Direct contact as a moderator of extended contact effects: Cross- 
sectional and longitudinal impact on outgroup attitudes, behavioral intentions, and attitude certainty. Personality and Social Psychology Bulletin, 36(12), 1662-1674.

Christ, O., Schmid, L., Lolliot, S., Swart, H., Stolle, D., Tausch, N., . . . Hewstone, M. (2014). Contextual effect of positive intergroup contact on outgroup prejudice. Proceedings of the National Academy of Sciences of the United States of America, 111(11), 3996-4000.

Cohen, D. A., Bing, H., Derose, K. P., Williamson, S., Marsh, T., Raaen, L., \& McKenzie, T. (2016). The paradox of parks in low-income areas: Park use and perceived threats. Environment and Behavior, 48(1), 230-245.

Cohen, D. A., Lapham, S., Evenson, K. R., Williamson, S., Golinelli, D., Ward, P., McKenzie, T. L. (2013). Use of neighborhood parks: Does socio-economic status matter? A four-city study. Public Health, 127(4), 325-332.

Cohen, D. A., McKenzie, T. L., Sehgal, A. S., Williamson, S., Golinelli, D., \& Lurie, N. (2007). Contribution of public parks to physical activity. American Journal of Public Health, 97(3), 509-514.

Cohen D. A., Setodji, C., Evenson, K. R., Ward, P., Lapham, S., Hillier, A., McKenzie, T.L. (2011). How much observation is enough? Refining the administration of SOPARC. Journal of Physical Activity \& Health, 8(8), 1117-1123.

Coley, R. L., Kuo, F. E., \& Sullivan, W. C. (1997). Where does community grow? The social context created by Nature in urban public housing. Environment and Behavior, 29(4), 468-492.

Cranz, G. (1982). The politics of park design: A History of urban parks in America. Cambridge, MA: MIT Press.

Cranz, G, \& Boland, M. (2004). Defining the sustainable park: A fifth model for urban parks. Landscape Journal, 23(2), 102-104.

Dannenberg, A. L., Frumkin, H., \& Jackson, R. J. (Eds.). (2011). Making healthy places: Designing and building for health, well-being and sustainability. Washington, DC: Island Press.

Deegan, M., Hehman, E., Gaertner, S. L., \& Dovidio, J. F. (2015). Positive expectations encourage generalization from a positive intergroup interaction to outgroup attitudes. Psychology Bulletin, 41(1), 52-65.

Derickson, K. D. (2016). The racial state and resistance in Ferguson and beyond. Urban Studies, 53(11), 2223-2237.

Derose, K. P., Han, B., Williamson, S., Cohen, D. A., \& RAND Corporation. (2015). Racial-ethnic variation in park use and physical activity in the city of Los Angeles. Journal of Urban Health, 92(6), 1011-1023.

Donovan, G. H., \& Prestemon, J. P. (2012). The effect of trees on crime in Portland, Oregon. Environment and Behavior, 44(1), 3-30.

Dovidio J. F., Gaertner, S. L., \& Kawakami, K. (2003). Intergroup contact: The past, present and the fu- ture. Group Processes and Intergroup Relations, 6(1), $5-21$.

Echols, L., Solomon, B. J., \& Graham, S. (2014). Same spaces, different races: What can cafeteria seating patterns tell us about intergroup relations in middle school? Cultural Diversity and Ethnic Minority, 20(4), 611-620.

Eisenman, T. S. (2013). Frederick Law Olmsted, green infrastructure, and the evolving city. Journal of Planning History, 12(4), 287-311.

Eisenman, T. S. (2016). Greening cities in an urbanizing age: The human health bases in the $19^{\text {th }}$ and early $21^{\text {st }}$ centuries. Change Over Time, 6(2), 216-247.

Eller, A., \& Abrams, D. (2004). Come together: Longitudinal comparisons of Pettigrew's reformulated intergroup contact model and the common ingroup identity model in Anglo-French and Mexican-American contexts. European Journal of Social Psychology, 34(3), 229-256.

Evenson, K. R., Jones, S. A., Holliday, K. M., Cohen, D. A., \& McKenzie, T. L. (2016). Park characteristics, use, and physical activity: A review of studies using SOPARC (System for Observing Play and Recreation in Communities). Preventive Medicine, 86, 153-166.

Evenson, K. R., Wen, F., Hillier, A., \& Cohen, D. A. (2013). Assessing the contribution of parks to physical activity using global positioning system and accelerometry. Medicine and Science in Sports and Exercise, 45(10), 1981-1987.

Fernandez, M., \& Witt, P. (2013). Attracting Hispanics to a public recreation center: Examining intergroup tension and historical factors. Journal of Leisure Research, 45(4), 423-444.

Francis, J., Wood, L. J., Knuiman, M., \& Giles-Corti, B. (2012). Quality or quantity? Exploring the relationship between public open space attributes and mental health in Perth, Western Australia. Social Science \& Medicine, 74(10), 1570-1577.

Francis, J., Giles-Corti, B., Wood, L., \& Knuiman, M. (2012). Creating sense of community: The role of public space. Journal of Environmental Psychology, 32(4), 401-409.

Gee, G. C., \& Ford, C. L. (2011). Structural racism and health inequities: Old issues, new directions. Du Bois Review, 8(1), 115-132.

Gee, G. C., Walsemann, K. M., \& Brondolo, E. (2012). Life course perspective on how racism may be related to health inequities. American Journal of Public Health, 102(5), 967-974.

Gobster, P. H. (1998). Urban parks as green walls or green magnets? Interracial relations in neighborhood boundary parks. Landscape and Urban Planning, 41(1), 43-55.

Gobster, P. H. (2002). Managing urban parks for a racially and ethnically diverse clientele. Leisure Science, 24(2), 143-159.

Grazuleviciene, R., Dedele, A., Danileviciute, A., Vencloviene, J., Grazulevicius, T., Andrusaityte, S., . . . 
Nieuwenhuijsen, M. J. (2014). The influence of proximity to city parks on blood pressure in early pregnancy. International Journal of Environmental Research and Public Health, 11(3), 2958-72.

Han, B., Cohen, D. A., Derose, K. P., Marsh, T., Williamson, S., \& Loy, S. (2015). Effectiveness of a free exercise program in a neighborhood park. Preventive Medicine Reports, 2, 255-258.

Harnik, P. (2010). Urban green: Innovative parks for resurgent cities. Washington, DC: Island Press.

Hartig, T., Mitchell, R., de Vries, S., \& Frumkin, H. (2014). Nature and Health. Annual Review of Public Health, 35, 207-228.

Ho, C-H., Sasidharan, V., Elmendorf, W., Willits, F. K., Graefe, A., \& Godbey, G. (2005). Gender and ethnic variations in urban park preferences, visitation and perceived benefits. Journal of Leisure Research, 37(3), 281-306.

Hodson, G., \& Hewstone, M. (2013). Advances in intergroup contact. London: Psychology Press.

Jacobs, J. (1961). The death and life of great American cities. New York: Random House.

Jamieson, J. P., Koslov, K., Nock, M. K., \& Mendes, W. B. (2013). Experiencing discrimination increases risk taking. Psychological Science, 24(2), 131-139.

Jones, A. P., \& Lachowycz, K. (2011). Greenspace and obesity: A systematic review of the evidence. Obesity Reviews, 12(5), e183-e189.

Jones, C. P. (2000). Levels of racism: A theoretic framework and a gardener's tale. American Journal of Public Health, 90(8), 1212-1215.

Kaczynski, A. T., \& Henderson, K. A. (2008). Parks and recreation settings and active living: A review of associations with physical activity function and intensity. Journal of Physical Activity and Health, 5(4), 619-632.

Kaczynski, A. T., Luke, R., Potwarka, M. A., \& Saelens, B. E. (2008). Association of park size, distance, and features with physical activity in neighborhood parks. American Journal of Public Health, 98(8), 1451-1456.

Kaczynski, A. T., Wilhelm Stanis, S. A., Hastmann, T. J., \& Besenyi, G. M. (2011). Variations in observed park physical activity intensity level by gender, race, and age: Individual and joint effects. Journal of Physical Activity and Health, 8(Suppl 2), S151-S160.

Kaplan, R., \& Kaplan, S. (1989). The experience of Nature: A psychological perspective. Cambridge, New York: Cambridge University Press.

Kaplan, S. (1995). The restorative benefits of Nature: Toward an integrative framework. Journal of Environmental Psychology, 15(3), 169-182.

Kazmierczak, A. (2013). The contribution of local parks to neighborhood social ties. Landscape and Urban Planning, 109(1), 31-44.

Keeley, M. (2011). The Green Area Ratio: An urban site sustainability metric. Journal of Environmental Planning and Management, 54(7), 937-958.

King, A., Glanz, K., \& Patrick, K. (2015). Technologies to measure and modify physical activity and eating environments. American Journal of Preventive Medicine, 48(5), 630-638.

Krieger, N. (1999). Embodying inequality: A review of concepts, measures, and methods for studying health consequences of discrimination. International Journal of Health Services, 29(2), 295-352.

Krieger, N. (2016). Living and dying at the crossroads: Racism, embodiment, and why theory is essential for a public health of consequence. American Journal of Public Health, 106(5), 832-833.

Kuo, F. E., Bacaicoa, M., \& Sullivan, W. C. (1998). Transforming inner-city landscapes: Trees, sense of safety, and preference. Environment and Behavior, 30(1), 28-59.

Kuo, F.E., \& Sullivan, W. C. (2001). Environment and crime in the inner city: Does vegetation reduce crime? Environment and Behavior, 33(3), 343-367.

Kuo, F. E., Sullivan, W. C., Coley, R. L., \& Brunson, L. (1998). Fertile ground for community: Inner-city neighborhood common spaces. American Journal of Community Psychology, 26(6), 823-851.

Lee, K. J., \& Scott, D. (2013). Interracial contact experience during recreational basketball and soccer: Korean American males' perspective. Journal of Leisure Research, 45(3), 267-294.

Levin, S., van Laar, C., \& Sidanius, J. (2003). The effects of ingroup and outgroup friendships on ethnic attitudes in college: A longitudinal study. Group Processes and Intergroup Relations, 6(1), 76-92.

McKenzie, T. L., Cohen, D. A., Sehgal, A., Williamson, S., \& Golinelli, D. (2006). System for Observing Play and Recreation in Communities (SOPARC): Reliability and feasibility measures. Journal of Physical Activity \& Health, 3, S208-S222.

McKinnon, R. A., Reedy J., Berrigan, D., \& Krebs-Smith, S. M. (2012). The National Collaborative on Childhood Obesity Research catalogue of surveillance systems and measures registry: New tools to spur innovation and increase productivity in childhood obesity research. American Journal of Preventive Medicine, 42(4), 433-435.

Maas, J., van Dillen, S. M. E., Verheij, R. A., \& Groenewegen, P. P. (2009). Social contact as a possible mechanism behind the relation between green space and health. Health \& Place, 15(2), 586-595.

Main, K. (2013). Planting roots in foreign soil? Immigrant place meanings in an urban park. Journal of Environmental Psychology, 36, 291-304.

Mills, C. (1997). The racial contract. Ithaca, NY: Cornell University Press.

Newman, O. (1972). Defensible space: Crime prevention through urban design. New York: Macmillan.

Olmsted, F. L. (1870). Public parks and the enlargement of towns. The Urban Design Reader, 28-34.

Peters, K., Elands, B., \& Buijs, A. (2010). Social interactions in urban parks: Stimulating social cohesion? Urban Forestry \& Urban Greening, 9(2), 93-100. 
Pettigrew, T. F. (1998). Intergroup Contact Theory. American Review of Psychology, 49(1), 65-85.

Pettigrew, T. F. (2016). In pursuit of three theories: Authoritarianism, relative deprivation, and intergroup contact. Annual Review of Psychology, 67, 1-21.

Pettigrew, T. F., \& Tropp, L. R. (2006). A meta-analytic test of intergroup contact theory. Journal of Personality and Social Psychology, 90(5), 751-783.

Putnam, R. D. (2000). Bowling alone. The collapse and revival of American community. New York: Simon and Schuster.

Quigg, R., Gray, A., Reeder, A., Holt, A., \& Waters, D. L. (2010). Using accelerometers and GPS units to identify the proportion of daily physical activity located in parks with playgrounds in New Zealand children. Preventive Medicine, 50(5), 235-240.

Reed, J. A., \& Hooker, S. P. (2012). Where are youth physically active? A descriptive examination of 45 parks in a southeastern community. Child Obesity, $8(2), 124-131$.

Reed, J. A., Hooker, S. P., Muthukrishnan, S., \& Hutto, B. (2011). User demographics and physical activity behaviors on a newly constructed urban rail/trail conversion. Journal of Physical Activity \& Health, 8(4), 534-542.

Reed, J. A., Price, A. E., Grost, L., \& Mantinan, K. (2012). Demographic characteristics and physical activity behaviors in sixteen Michigan parks. Journal of Community Health, 37(2), 507-512.

Rios, R., Aiken, L. S. \& Zautra, A. J. (2012). Neighborhood contexts and the mediating role of neighborhood social cohesion on health and psychological distress among Hispanic and Non-Hispanic residents. Annals of Behavioral Medicine, 43(1), 50-61.

Rishbeth, C. (2001). Ethnic minority groups and the design of public open space: An inclusive landscape? Landscape Research, 26(4), 351-366.

Schuyler, D. (1986). The new urban landscape: The redefinition of city form in nineteenth-century America. Baltimore and London: Johns Hopkins University Press.

Seeland, K., Dübendorfer, S., \& Hansmann, R. (2009). Making friends in Zurich's urban forests and parks: The role of public green space for social inclusion of youths from different cultures. Forest Policy and Economics, 11(1), 10-17.

Sharaievska, I., Stodolska, M., Shinew, K. J., \& Kim, J. (2010). Perceived discrimination in leisure settings in Latino urban communities. Leisure, 34(3), 295-326.

Shores, K. A., \& West, S. T. (2010). Rural and urban park visits and park-based physical activity. Preventive Medicine, 50, S13-S17.

Solecki, W. D., \& Welch, J. M. (1995). Urban parks: Green spaces or green walls? Landscape and Urban Planning, 32(2), 93-106.

Song, C., Ikei, H., Igarashi, M., Miwa, M., Takagaki, M., \& Miyazaki, Y. (2014). Physiological and psychological responses of young males during spring-time walks in urban parks. Journal of Physiological Anthropology, 33(8), 1-7.

Stodolska, M., Peters, K., \& Horolets, A. (2016). Immigrants' adaptation and interracial/interethnic interactions in natural environments. Leisure Sciences, 1-17. doi:10.1080/01490400.2016.1213676

Sturm, R., \& Cohen, D. (2014) Proximity to urban parks and mental health. The Journal of Mental Health Policy and Economics, 17(1), 19-24.

Sugiyama, T., Leslie, E., Giles-Corti, B., \& Owen, N. (2008). Associations of neighbourhood greenness with physical and mental health: Do walking, social coherence and local social interaction explain the relationships? Journal of Epidemiology and Community Health, 62(5), e9.

Sullivan, W. C., Kuo, F. E., \& DePooter, S. (2004). The fruit of urban nature: Vital neighborhood spaces. Environment and Behavior, 36(5), 678-700.

Ulrich, R. S. (1984). View through a window may influence recovery from surgery. Science, 224(4647), 420-421.

Van Dyck, D., Sallis, J. F., Cardon, G., Deforche, B, Adams, M. A., Geremia, C., \& De Bourdeaudhuij, I. (2013) Association of neighborhood characteristics with active park use: An observational study in two cities in the USA and Belgium. International Journal of Health Geographics, 12(1), 1.

Ward, P., McKenzie, T. L., Cohen, D., Evenson, K. R., Golinelli, D., Hillier, A., Williamson, S. (2014). Physical activity surveillance in parks using direct observation. Preventing Chronicic Disease, 11.

Watson, K. B., Harris, C. D., Carlson, S. A., Dorm, J. M., \& Fulton, J. E. (2016). Disparities in adolescents' residence in neighborhoods supportive of physical activity-United States, 2011-2012. MMWR Morbidy and Mortality Weekly Report, 65, 59601.

Weiss, C. C., Purciel, M., Bader, M., Quinn, J. W., Lovasi, G., Neckerman, K. M., \& Rundle, A. G. (2011). Reconsidering access: Park facilities and neighborhood disamenities in New York City. Journal of Urban Health, 88(2), 297-310.

West, P. C. (1989). Urban region parks and Black minorities: Subculture, marginality, and interracial relations in park use in the Detroit metropolitan area. Leisure Sciences, 11(1), 11-28.

Wheater, C. P., Potts, E., Shaw, E. M., Perkins, C., Smith, H., Casstles, H., . . Bellis, M. A. (2007). Returning urban parks to their public health roots. Manchester and Liverpool: Manchester Metropolitan University and Liverpool John Moores University.

Wilson, J. Q., \& Kelling, G. L. (1982). Broken windows: The police and neighborhood safety. The Atlantic Monthly, 249(3), 29-38.

Young, R. F. (2011). Planting the living city: Best practices in planning green infrastructure-Results from major US cities. Journal of the American Planning Association, 77(4), 368-381. 


\section{About the Authors}
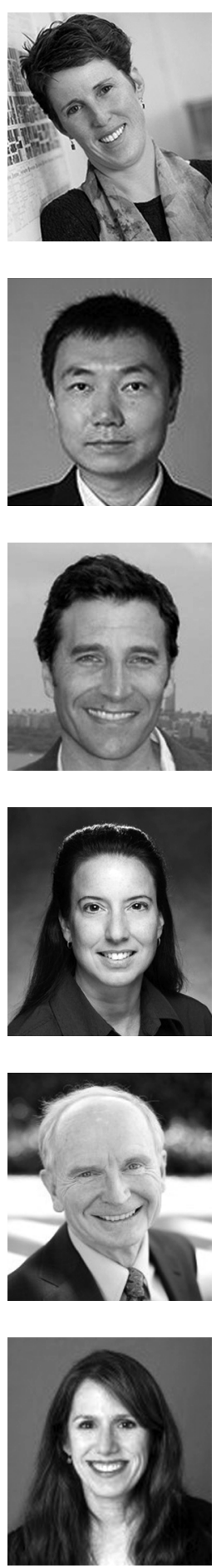

Amy Hillier is an Associate Professor at the School of Design and School of Social Policy \& Practice at the University of Pennsylvania. Her research focuses on spatial disparities across race and income in housing and public health. Her most recent work focused on the needs of LGBTQ youth populations in schools, social services, and health care settings.

Bing Han is a statistician at the RAND Corporation and a professor at the Pardee RAND Graduate School. His research interests include large-scale simultaneous inference, nonparametric statistics, causal inference, and longitudinal data. He is an applied statistician working in several policy domains, including public health, education evaluation, and science and technology.

Theodore S. Eisenman is an Assistant Professor in Landscape Architecture at the University of Massachusetts, Amherst. His principle scholarly interest concerns the historical, scientific, cultural, and design bases of urban greening, defined here as the introduction or conservation of outdoor vegetation in cities.

Kelly R. Evenson is a Research Professor at the University of North Carolina-Chapel Hill in the Gillings School of Global Public Health who specializes in physical activity epidemiology. Her research focuses on physical activity and sedentary behavior, with specific areas related to measurement, surveillance, and intervention.

Thomas L. McKenzie is Emeritus Professor of Exercise and Nutritional Sciences at San Diego State University and former Adjunct Professor, Department of Pediatrics, University of California, San Diego. He is widely known for his expertise in designing and assessing physical activity programs for diverse populations.

Deborah A. Cohen is a senior natural scientist at the RAND Corporation. Her areas of interest include how structural environmental factors-social and physical-influence health. She has studied how neighborhood parks influence physical activity and how community characteristics affect health disparities and health. 